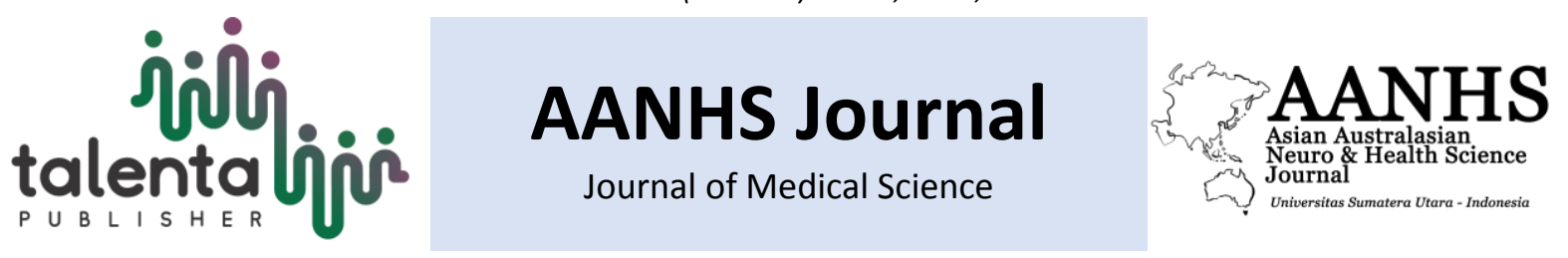

\title{
Penetrating Brain Injury In Children
}

\author{
Mutammamin Ula ${ }^{1}$, Ridha Dharmajaya ${ }^{2}$ \\ ${ }^{I}$ Neurosurgery Resident, Departement of Neurosurgery, University of Sumatera Utara, Haji Adam Malik \\ Hospital,Medan \\ ${ }^{2}$ Head Department of Departement of Neurosurgery, University of Sumatera Utara, Haji Adam Malik \\ Hospital,Medan
}

\begin{abstract}
Accidental penetrating brain injury through transorbital route is an unusual occurrence in emergency practice of civilian cases. At time, it could be potentially life threatening. We report an interesting case of transorbital penetrating brain injury with an iron stick in a 12-year-old female patient. The stick was removed successfully through transorbital exploration, without any neurovascular complications. A 12-year-old female presented to our emergency department with injury to his right eye. History revealed that she was practicing marching band in her school as the leader. As she thrown the iron stick, she lost balance and that iron stick entered into her right supraorbital. Her Glasgow Coma Scale (GCS) score, on admission, was 15. There was circumferential laceration on the right supraorbital, flat margins, visible iron stick penetration with diameter $3 \mathrm{~cm}$ but no active bleeding was found. Rest of the physical and neurological examination findings were within normal limits. He was resuscitated promptly according to the advanced trauma life support system. Intravenous fluids are given and efforts are taken to maintain high blood oxygen levelsManagement of patients with transorbital brain injuries and foreign bodies in situ should follow basic surgical principles, including removal of the object under direct vision in order to reduce further brain tissue damage by the foreign bodies catching on bone fragments. Following removal of the foreign body, thorough debridement with removal of all involved skull bone and foreign materials, hematoma evacuation followed by careful hemostasis along the trajectory, and meticulous dural closure to reduce the possibility of CSF fistula are mandatory. A transorbital or transcranial approach can be chosen depending on the location of the fragment. In conclusion, transorbital penetrating brain injury caused by an iron stick is a rare but fatal event. High index of suspicion toward the presence of foreign bodies and emergent surgical intervention is to be considered in spite of consistent lack of evidence on CT scan. Retrieval should be performed on the operating table under direct vision only after preoperative imaging of neurovascular structures.
\end{abstract}

Keyword: Penetrating brain injury, Iron Stick

Received [4 Nov 2019] | Revised [28 Nov 2019] | Accepted [30 Nov 2019]

\section{Introduction}

Penetrating brain injury is common in modern life. While the incidence of penetrating brain injury continues to rise and was associated with over 34,000 deaths in United States in 2015

*Corresponding author at: mutamaminula@gmail.com

E-mail address: mutamaminula@gmail.com 
with a mortality rates of penetrating brain injury is as high as $85 \%$. Literature of penetrating brain injury has largely been separated into civilian and military settings. Penetrating brain injury is associated with high mortality from a myriad of mechanisms. Energy and speed of entry deciding the factor of pathophysiological of penetrating brain injury. Three mechanisms that have been reported are laceration and crushing, cavitations and shockwaves. ${ }^{1}$

Accidental penetrating brain injury is relatively uncommon representing about $0.4 \%$ of all head injuries. Transorbital penetrating brain injury secondary to a non-projectile foreign body is a rare incident. Narrating such a rare case of transorbital penetrating brain injury with an iron stick is interesting to report. As there is significant lack of data pertaining to the management of penetrating brain damage by foreign body, it is pertinent to understand the mechanism, anatomy, and treatment of such injuries. ${ }^{1,2}$

\section{Case Report}

A 12-year-old female presented to our emergency department with injury to his right eye. History revealed that she was practicing marching band in her school as the leader. As she thrown the iron stick, she lost balance and that iron stick entered into her right supraorbital. There was no history of syncope. the patient experienced vomiting 3 times before being taken to hopspital. On physical examination, the patient had a pulse rate of 98 per minute and blood pressure of 123/69 mm Hg. Her Glasgow Coma Scale (GCS) score, on admission, was 15. Left and right pupil was normal in size and reacting to light. There was circumferential laceration on the right supraorbital, flat margins, visible iron stick penetration with diameter $3 \mathrm{~cm}$ but no active bleeding was found. Rest of the physical and neurological examination findings were within normal limits. He was resuscitated promptly according to the advanced trauma life support system. We treated the patient with craniectomy and did the debridement on the patients, we also did frontal sinus obliteration and cranialization, and removed the non missile corpus. 


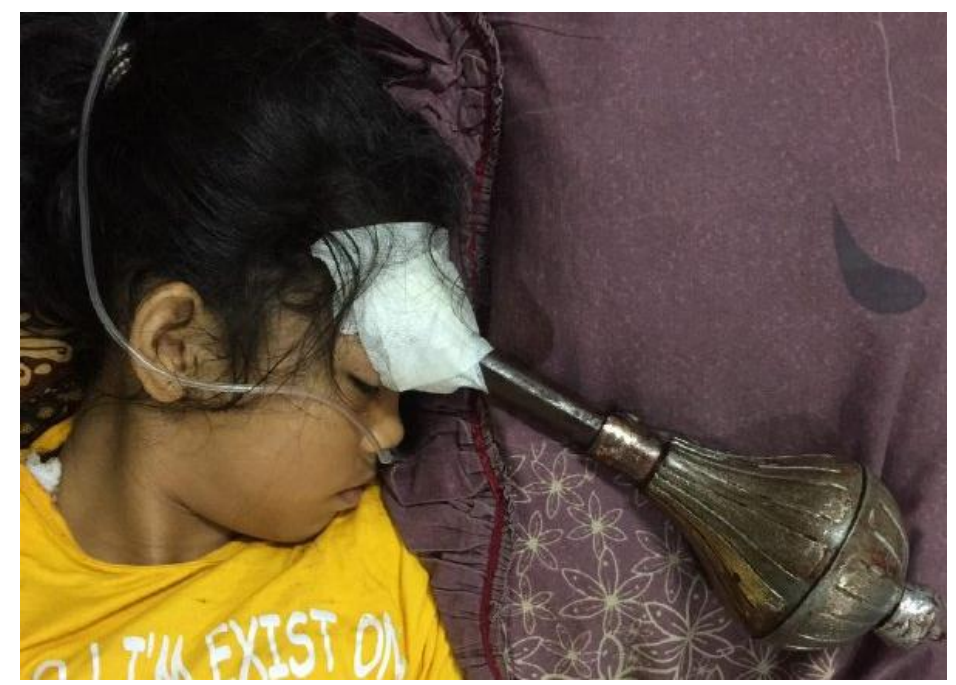

Image 1. Clinical Appearance of the Patient

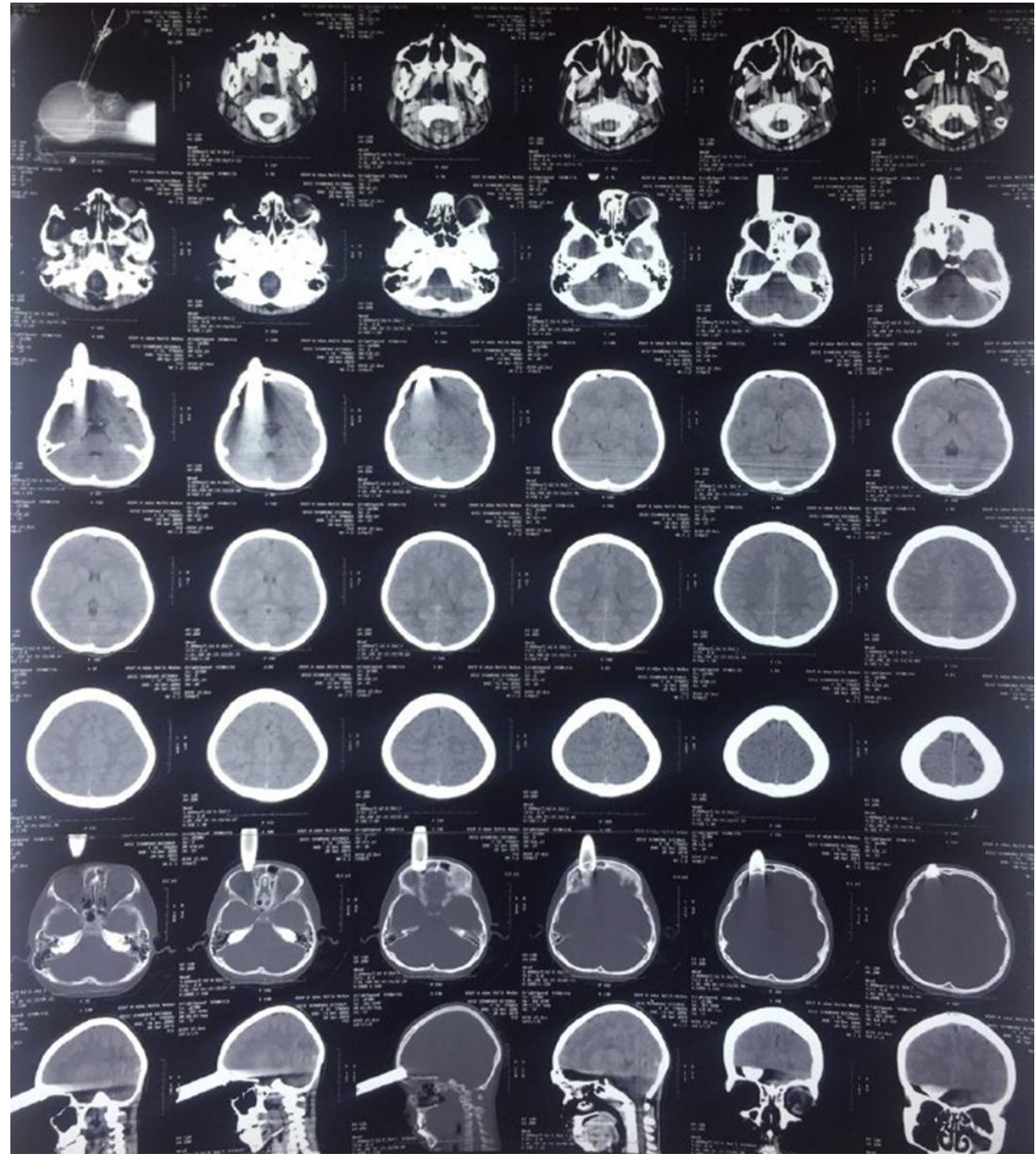

Image 2. Non Contract CT scan of the patients showing penetrating of foreign object from supraorbital through the cerebral cortex 


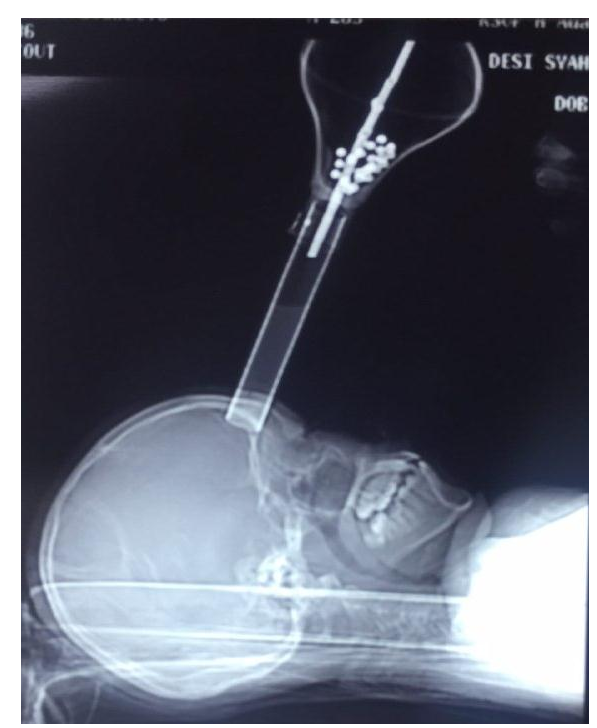

Image 4.

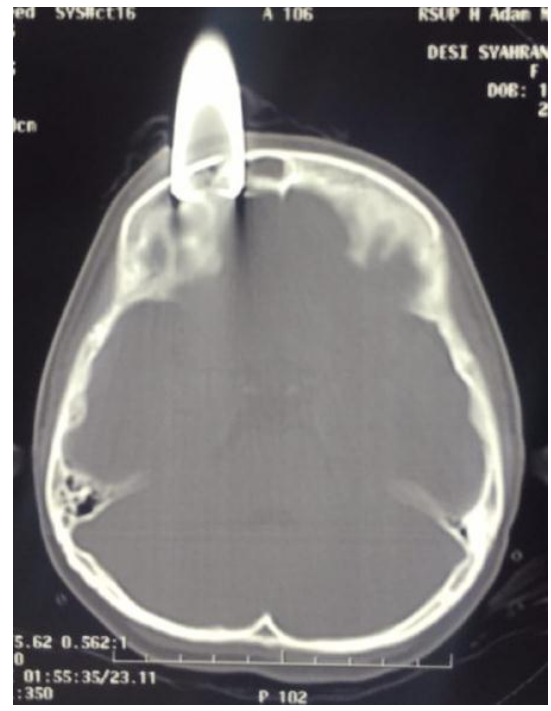

Image 5.

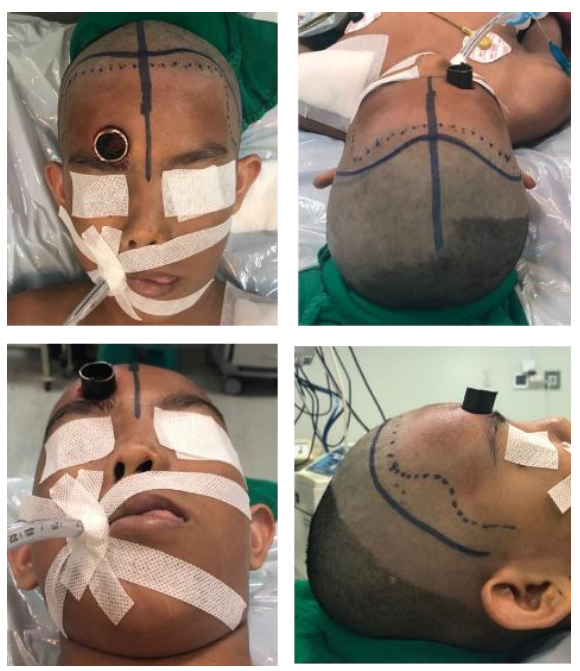

Image 6. Preoperative image of Patients

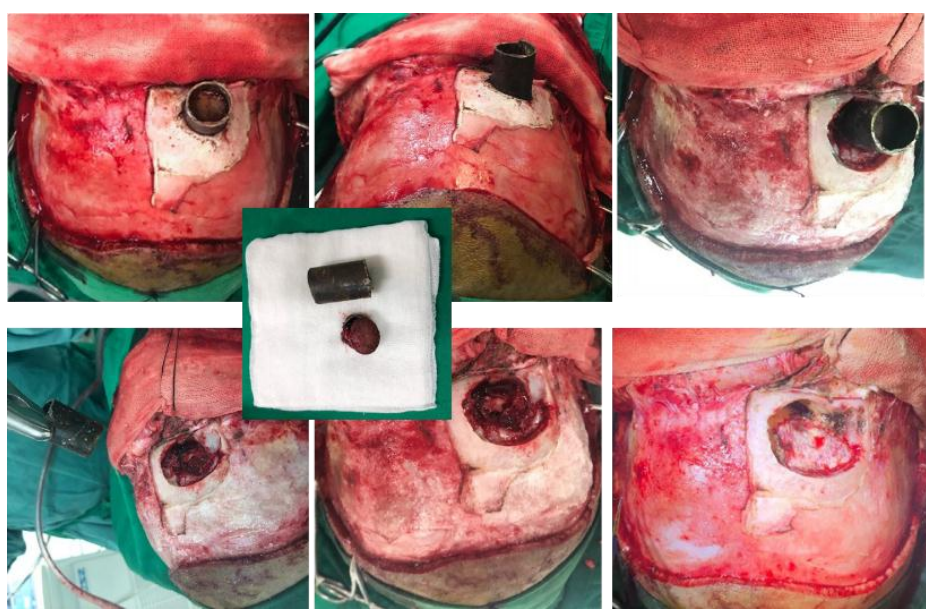

Image 7. Intraoperative Image of Patients 


\section{Discussion}

In the prehospital settings, patients should be stabilize but do onot remove penetrating objects and patients should be transported quickly to a location capable of providing definitive care. In the emergency department, resuscitation and stabilization should be provided by stabilizing ABCDE based on Advanced Trauma Life Support guidelines. Perform neurological examinations including GCS and document well and suggest the sign of intracranial hypertension. $^{3,4}$

If the patients is hemodynamically stable, obtain a Computed Tomography (CT scan) of the head to evaluate the presence of mass lesion (hematoma) or cerebral edema. Certain factors are important in critical decision making of penetrating brain injury, with consideration of sites of entry and exit wounds, presence of intracranial fragments, relationship to both blood vessels and air containing skull-base, presence of intracranial air, trans-ventricular injury, basal ganglia and brainstem injury, whether the foreign body crosses midline or not, presence of multilobar injury, presents of basal cisterns effacement, brain parenchymal herniation and presence of any associated mass effects. ${ }^{5,6}$

Patients should receive both medical and surgical management. Surgical intervention should be done if the patients have hematoma present. Early decompression with conservative debridement of the brain may be needed. ${ }^{7}$

In this patients, the most appropriate management in the field is to leave the transorbital object in situ and transport the patient to the trauma center carefully. Intravenous fluids are given and efforts are taken to maintain high blood oxygen levels. Management of patients with transorbital brain injuries and foreign bodies in situ should follow basic surgical principles, including removal of the object under direct vision in order to reduce further brain tissue damage by the foreign bodies catching on bone fragments. ${ }^{8,9}$

Following removal of the foreign body, thorough debridement with removal of all involved skull bone and foreign materials, hematoma evacuation followed by careful hemostasis along the trajectory, and meticulous dural closure to reduce the possibility of CSF fistula are mandatory. Except in high-velocity injuries, most penetrating injuries, regardless of size of penetrating bodies, are rarely associated with major neurological symptoms. Early surgical exploration is likely to be successful in cases of retained foreign body. A transorbital or transcranial approach can be chosen depending on the location of the fragment. ${ }^{8,9}$

\section{Conclusion}

In conclusion, transorbital penetrating brain injury caused by an iron stick is a rare but fatal event. High index of suspicion toward the presence of foreign bodies and emergent surgical intervention is to be considered in spite of consistent lack of evidence on CT scan. Retrieval 
should be performed on the operating table under direct vision only after preoperative imaging of neurovascular structures

\section{REFERENCES}

[1] Alao T and Waseem, M. 2019. Penetrating Head Trauma. NCBI and self-inflicted injury survivors. Arch Phys Med Rehabil. 2017;98(11):

[2] Bertisch H, Krellman JW, Bergquist TF, Dreer LE, Ellois V, Bushnik T. Characteristics of firearm brain injury survivors in the Traumatic Brain

[3] Domenicucci M, Qasho R, Ciappetta P, Vangelista T, Delfini R. Surgical treatment of penetrating orbito-cranial injuries. Case report. J Neurosurg Sci 1999;43:229-34

[4] Fathalla H, Ashry A, El-Fiki A. Managing military penetrating brain injuries in the war zone: lessons learned. Neurosurg Focus. 2018 Dec 01;45(6):E6. gunshot injuries to the brain. J Trauma. 2007;62(6):1446-1451

[5] Harmon, LA. Haase, DJ. Kufera, JA., et al. 2019. Infection after penetrating brain injury-An Eastern Association for the Surgery of Trauma multicenter study oral presentation at the 32nd annual meeting of the Eastern Association for the Surgery of Trauma, January 15-19, 2019, in Austin, Texas. Journal of Trauma Acute Care Surgery, Vol. 87 number 1. Wolters-Kluwers. Injury Model Systems (TBIMS) National Database: a comparison of assault

[6] KimTW, Lee JK,Moon KS,KwakHJ, Joo SP, Kim JH, Kim SH. Penetrating

[7] Milton J, Rugino A, Narayan K, Karas C, Awuor V. A Case-Based Review of the Management of Penetrating Brain Trauma. Cureus. 2017 Jun 12;9(6):e1342

[8] O'Neill OR, Gilliland G, Delashaw JB, Purtzer TJ. Transorbital penetrating head injury with a hunting arrow: Case report. Surg Neurol 1994;42:494-7

[9] Paiva WS, Saad F, Cravalhal ES, Amorim RL, Figueiredo EG, Teixeira MJ. Transorbital stab penetrating brain injury: Report of a case. Ann Ital Chir 2009;80:463-5,review of current evaluation and management concepts. J Neurol Neurophysiol. 